九州大学学術情報リポジトリ

Kyushu University Institutional Repository

\title{
Age Composition of Summer Colonies in the Japanese House-dwelling Bat, Pipistrellus abramus
}

Funakoshi, Kimitake

Zoological Laboratory, Faculty of Agriculture, Kyushu University

Uchida, Teruaki

Zoological Laboratory, Faculty of Agriculture, Kyushu University

https://doi.org/10.5109/23758

出版情報: 九州大学大学院農学研究院紀要. 27 (1/2)，pp.55-64，1982-10. Kyushu University バージョン：

権利関係 : 


\title{
Age Composition of Summer Colonies in the Japanese House-dwelling Bat, Pipistrellus abramus*
}

\author{
Kimitake Funakoshi† and Teru Aki Uchida \\ Zoological Laboratory, Faculty of Agriculture, \\ Kyushu University 46-06, Fukuoka 812
}

(Received June 14, 1982)

\begin{abstract}
Age structure of summer colonies in P. abramus was studied by banding and counting dental annuli. Females less than two years of age constituted the majority of the members in the relatively large-sized A and B colonies investigated by the banding-recapture method, whereas older females, and males more than one year of age decreased rapidly. A similar age composition was found in the large $\mathrm{C}$ population and the small D colony, whose age structures were determined by counting incremental lines in dentine. The disappearance rate during the period from weaning to one year of age was 18-29\% in females and $85-96 \%$ in males. The low ratio in females is probably attributable to their remaining in the nursery colony even after weaning, and to their tolerance for scanty food and severe weather. The female disappearance rate from one to three years of age was relatively low, while that from four to five years of age was very high. After the first year of life, male mortality appears to be always higher than the female one. That the oldest age determined for P. abramus was five years in females and three years in males, suggests that P. abramus is a fairly short-lived species in vespertilionid bats.
\end{abstract}

\section{INTRODUCTION}

In a previous paper (Funakoshi and Uchida, 1978) on annual activity of Pipistrellusabramus, we reported such ecological aspects as permanent residence, colony size, seasonal changes in sex composition of the adults and young in each colony, litter size and sexual maturity. The purpose of this study was to examine thoroughly the age structure of the summer colonies by counting annual layers in the tooth dentine. Survival or disappearance rate in each age class was also investigated with mark-recapture technique.

Age determination by counting incremental growth lines in bat tooth cementum and dentine was described by Christian (1956) for Eptesicus fuscus and by Klevezal and Kleinenberg (1967) for Nyctalus noctula and Myotis myotis. Linhart (1973) and Lord et al. (1976) utilized these growth lines to estimate population age structure of Desmodus rotundus. Schowalter et al. (1978) showed

* Reprint request should be addressed to Prof. T. A. Uchida.

$\dagger$ Present address: Department of Anatomy, Faculty of Medicine, Kyushu University, Fukuoka 812. 
that longevity of E.fuscus and longevity and age structure of Myotis lucifugus, which were determined by examining the annuli in the teeth, agreed with those obtained from Iongterm banding studies (Goehring, 1972; Humphrey and Cope, 1976).

To determine whether or not the technique of counting dental annuli would be effective for aging P.abramus, we first checked incremental growth lines in the canine and molar tooth dentine of several bats of known age. Afterwards, the same technique was employed to determine the age composition of two populations of $P$. abramus collected in summer. On the basis of the results, we discussed the population dynamics of this species and the possible factors limiting the number of the bats in each age class.

\section{MATERIALS AND METHODS}

Of 25 colonies examined in Fukuoka City, two were selected for repeated banding because of their relatively large populations. Almost all the bats in one colony (A) had been banded by Mr. K. Marumo from July to November 1971. After that, we recaptured them from June to September 1973, and determined the age structure. The bats in the other colony (B) were also banded at intervals of from one to two weeks during the active period of June-September 1973, June-September 1974 and the preweaning period of June-July 1975; but after late July 1975 the banding was discontinued, because the house in which they roosted was destroyed. Although the age of bats which had been banded as young was accurately determined every year, that of bats which had been marked as adults for the first time remained unknown.

When determining age by counting dental annuli, the teeth of age-known specimens were examined first, and the applicability of the method was checked; mandibular teeth of 7 age-known females (2 one year olds, 3 two year olds, 2 three year olds), which had been banded in their first summer respectively, were examined by the following method. A mandible from each bat was decalcified in a solution of three parts formalin, five parts formic acid and 20 parts distilled water for about $60 \mathrm{~h}$. The jaw was then washed in running water for $6 \mathrm{~h}$. It was then embedded in paraffin and sectioned on a rotary microtome at $8 \mu \mathrm{m}$. These sections were then mounted on slides and stained with Delafield's hematoxylin, and observed at $100 \times$ and $400 \times$ under transmitted light. After the presence of annuli was confirmed by examination of the layers darkly stained in the tooth dentine, the following specimens of unknown age were examined: 106 bats $\left(88\right.$ 우, 18 $\left.0^{\circ}\right)$ captured at the $\mathrm{C}$ population in a factory in Fukuoka City just after parturition from 5 to 13 July 1965 and 11 bats (우) captured at the relatively small D colony in Fukuyama City just before parturition on 23 June 1979.

\section{RESULTS}

On the basis of the data obtained by banding, it was revealed that there 
was no individual exchange between two or more colonies. The 69 bats forming the A colony in June-September 1973 consisted of 52 females and 17 males; 8 females were more than three years old, 12 two years old, 13 one year old and 19 juveniles, while 2 males were one year old and 15 were juveniles (Table 1). Therefore, the females less than two years of age constituted a majority in the A colony, and the females more than three years of age decreased in number rapidly. The $B$ colony was composed of 37 bats (36우우,1ð) during the period from June to July 1975, excluding young not yet weaned; 8 females were more than three years old, 11 two years old and 17 one year old, while 1 male was one year old (Table 2). The females less than two years of age constituted the greater part as in the A colony.

Table 1. Changes in survival number in different age and sex groups at the A colony proper of P. abramus based on the banding-recapture method in the summer of 1971 and 1973.

\begin{tabular}{|c|c|c|c|c|c|c|c|c|c|}
\hline \multirow{2}{*}{$\begin{array}{c}\text { Period } \\
\text { examined }\end{array}$} & \multicolumn{8}{|c|}{ Number of bats born } & \multirow[b]{2}{*}{ Total } \\
\hline & $\begin{array}{l}\text { before } \\
\text { 우우 }\end{array}$ & $\begin{array}{r}1970 \\
\widehat{\partial}\end{array}$ & $\begin{array}{l}\text { in } \\
\text { 우우 }\end{array}$ & ${ }^{1971}$ ठठ & $\begin{array}{l}\text { in } \\
\text { 우 }+9\end{array}$ & $\begin{array}{l}1972 \\
\text { ठठ ठ }\end{array}$ & $\begin{array}{r}\text { in } \\
\text { 우우 }\end{array}$ & 973 & \\
\hline 1973(June-Sept.) & 28 & $\begin{array}{l}3 \\
0\end{array}$ & 10 & 10 & $\overline{13}$ & $\overline{2}$ & $\overline{19}$ & 15 & $\begin{array}{l}55 \\
69\end{array}$ \\
\hline
\end{tabular}

Table 2. Changes in survival number in different age and sex groups at the B colony proper of $\mathbf{P}$. abramus based on the banding-recapture method in the summer of 1973-1975.

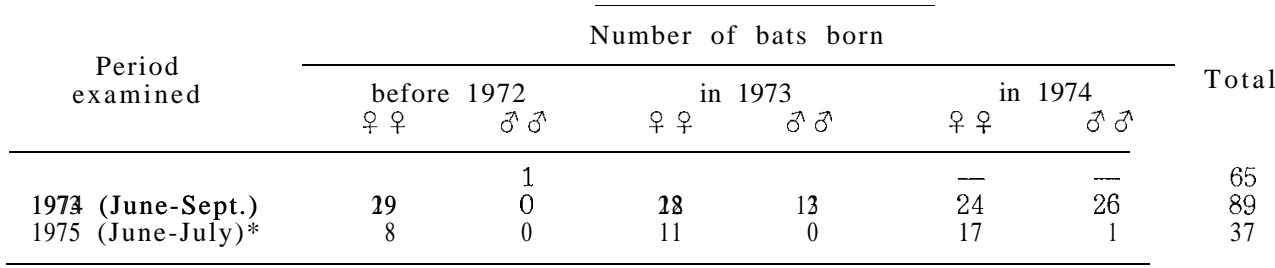

* Number of the volant young born in 1975 could not be obtained, because the roost was broken in late July 1975.

It was histologically determined that a dark layer in the dentine of the roots of canine and cheek teeth forms every winter, and can be used as an age criterion (Fig. 1). The teeth of 106 bats in the $\mathrm{C}$ population and of 11 bats in the $\mathrm{D}$ colony were then analyzed: in the former 2 were five-year-old females, 7 four-year-old females, 22 three-year-olds (21우우, 1 § ), 34 two-year-

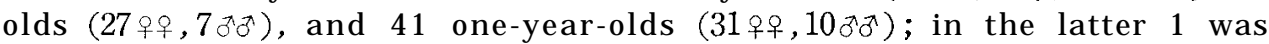
a four-year-old female, 1 a three-year-old female, 4 two-year-old females, and 5 one-year-old females. The age as determined by teeth roughly agreed with the banding evidence. The longest survival period in this bat was five years in female and three years in male, respectively. 

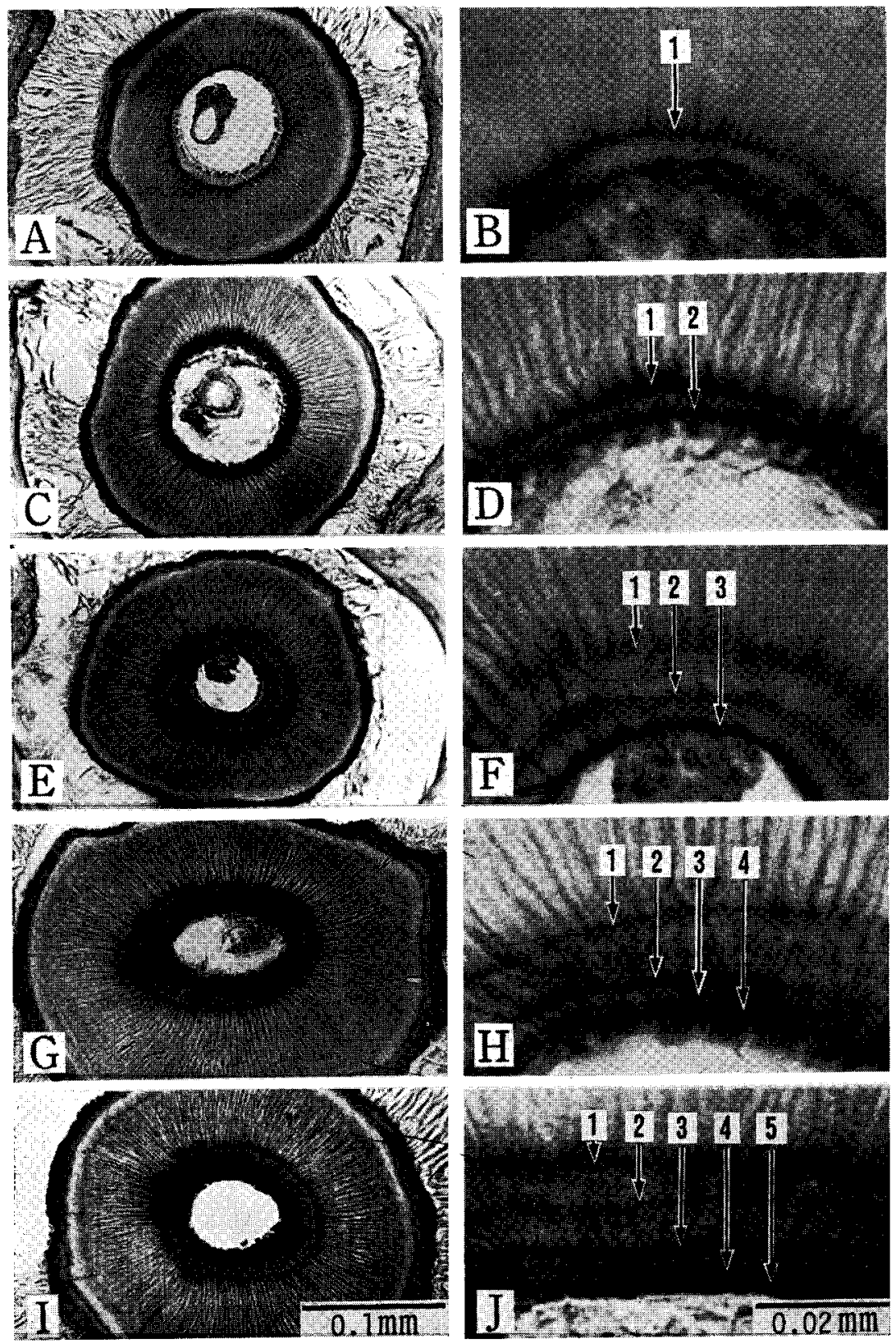

Fig. 1. Cross sections of the root dentine of the lower second molar in P. abramus, stained with hematoxylin. A and B, one year old; C and $D$, two years old; $E$ and $F$, three years old; $G$ and $H$, four years old; $I$ and $J$, five years old. Arabic numerals indicate annual dark layers occurred in each year. 


\section{DISCUSSION}

\section{Preweaning mortality}

Before taking up the postnatal mortality in $P$. abramus, we refer to the prenatal one. Considering that the number of ovulated ova is usually three and less, and that the litter size ranges from one to three, fertilization rate appears to be very high and prenatal mortality seems extremely low (Uchida, 1953). Based on the number of fertilized ova and embryos in Pipistrellus subflavus bearing normally two young (Wimsatt, 1945), prenatal mortality is about $26 \%$. The prenatal mortality in E. fuscus is $34 \%$ (Kunz, 1974).

In $P$. abramus, the volant young reach sexual maturity in autumn of their first year, and females become gravid in the following spring (Funakoshi and Uchida, 1978). The average litter size is 2.3 , relatively large for vespertilionids; at birth no significant difference in the sex ratio of the 17 males and 16 females is noted (Chi-square $0.03,0.90>p>0.80$ ), and the number of newborn young decreases to about half in the course of nursing (Funakoshi and Uchida, 1978, 1981). With 54 young males and 65 young females captured in June-September (Tables 1 and 2), no significant difference in the sex ratio

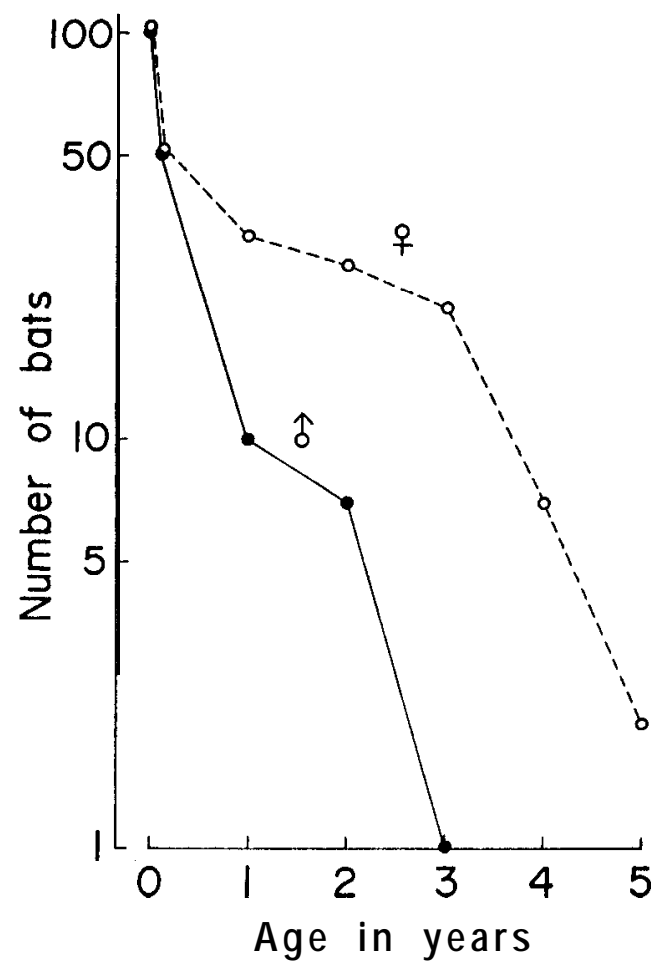

Fig. 2. Age composition of the C population in P. abramus from Fukuoka City in July 1965. 


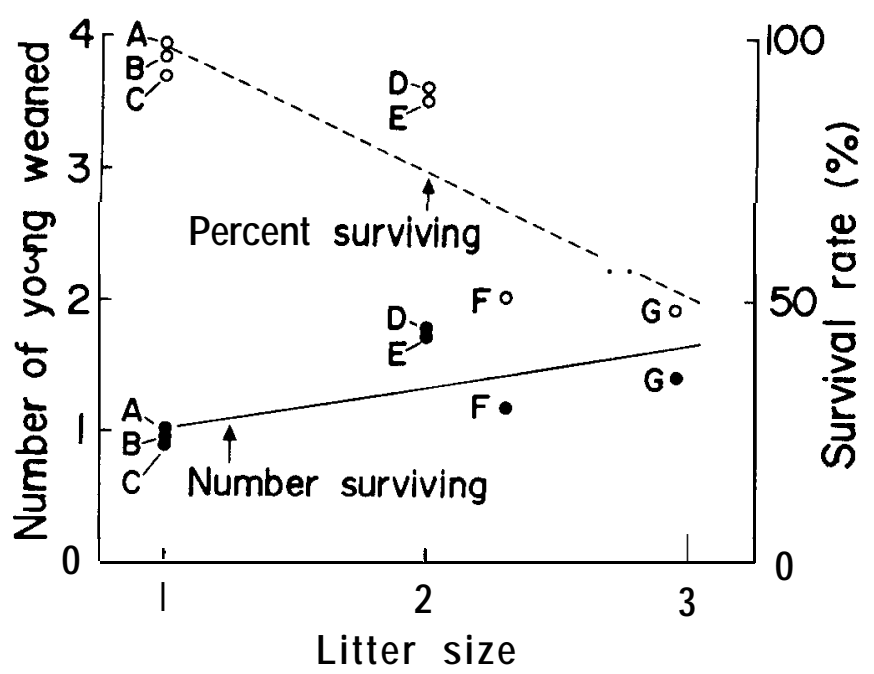

Fig. 3. Correlation between litter size and number of young weaned in bats. A, Tadarida brasiliensis mexicana (Herreid, 1967) ; B, Plecotus tow nsendi (Humphrey and Kunz, 1976); C, Myotis sodalis (Humphrey et al., 1977); D, Eptesicus fuscus (Christian, 1956; Kunz, 1974) ; E, Myotis austroriparius (Foster et al., 1978); F, P. abramus (this paper); G, Lasiurus borealis (Jones ef al., 1900 ; Kunz, (ŶT1).

(Chi-square 1.02, 0.50>p >0. 30) was found. From the above, we may assume that if all of the 88 adult females in the $\mathrm{C}$ population became pregnant, they would produce about 202 young and only half of the young would survive to the weaning age. The estimated numbers, and actual numbers of different age group determined by the histological method (Fig. 1) and sex group in the $\mathrm{C}$ population are semilogarithmically plotted (Fig. 2). Mortality of young bats from birth to weaning varies with the species; as litter size becomes larger, preweaning mortality more increases (Fig. 3).

As for the factors affecting mortality in young bats from birth to weaning, competition among young for milk and success of parental care may alter their survival. The latter seems generally related to litter size (Foster et al., 1978), i.e. the lower the degree of the care is, the larger the mortality rate of young seems to become. In this connection, in Myotisaustrariparius low preweaning survival results from certain death when young fall into water under the roost, without parental retrieval (Foster et al., 1978). Predation seems to be one of the important factors limiting the number of suckling young (Taylor, 1954; Rice, 1957; Mumford, 1969; Foster et al., 1978).

Disappearance rate during the period from weaning to one year age

The mortality or disappearance rate during the period from weaning to one year age is 18 or $29 \%(4 / 22,7 / 24)$ in females and 85 or $96 \%(11 / 13,25$ / 26 ) in males (Table 2). In the other vespertilionid bats, the values for first-year survivorship in female young Nycticeius humeralis are as low as 23 to 
$32 \%$ (Humphrey and Cope, 1970). Return of $44 \%$ to the nursery colony in the following spring in young female Plecotus townsendii [Corynorhinus rafinesquei intermedius], indicates that the dispersal or death rate of the young females is very high (Pearson et al., 1952). In $E$. fuscus the mortality rate combined both sexes is about $62 \%$ (Beer, 1955) or $40 \%$ (Goehring, 1972) for the first year after banding; the mortality or disappearance rate in the same species is higher in juveniles than in adults (Brenner, 1968). In some species, such as P. subflavus (Davis, 1966), Miniopterus schreibersi (Dwyer, 1966; Kuramoto et al., 1975), M. lucifugus (Humphrey and Cope, 1976), D.rotundus (Lord et al., 1976), Myotis sodalis (Humphrey and Cope, 1977), Myotis macrodactylus (Kuramoto et al., 1978) and Myotis grisescens (Stevenson and Tuttle, 1981), mortality rates in both sexes for the first year after banding are higher than those for the subsequent years. Namely, in most species mortality or disappearance rate during the period from weaning to one year of age is as high as $40-60 \%$. In $P$. abramus most of the females tend to remain in their nursery colony even after weaning (Funakoshi and Uchida, 1978). This tendency may be one of the most important factors lowering the disappearance rate. On the other hand, most of the males tend to disperse, which fact may heighten their disappearance rate after weaning.

Growth success and survival of volant young $M$. grisescens are closely correlated with the distances traveled by the colonies to their feeding areas (Tuttle, 1976). Accidents while flying or seeking shelter constitute the major source of the mortality, and the mortality within nursery and winter roosts is negligible (Humphrey and Cope, 1976). On the other hand, some juvenile $M$. lucifugus do not accumulate as much fat as do adults, enter hibernation later and have poorer survival; and thus insufficient fat storage might be a mortality factor in first-year bats of other species, too (Davis and Hitchcock, 1965; Davis, 1966). The most important cause of mortality in volant young $P$. abvamus may be based also on the food condition especially in late autumn, winter and early spring when not only unstable weather but also food shortage is apt to occur. As mentioned above, however, the mortality or disappearance rate of the female $P$. abramus (18 or $29 \%$ ) is very low as compared with those of the other species. Therefore, it is considered that in female $P$. abramus tolerance for scanty food and severe weather' is stronger than those in the other species.

\section{Disappearance rate of bats more than one year of age and longevity}

Disappearance rate is $39 \%(7 / 18)$ for the second year in females banded as young (Table 2). Using the data in Fig. 2, a life table for female $P$. abvamus is made (Table 3), although such a small population is insufficient to do so. The mortality in females from three to five years of age is higher than that in the younger females (Fig. 2; Tables 1-3), as supported also by the $\mathrm{D}$ colony. As for the sexual difference in mortality, it seems that in $P$. abramus the male mortality becomes higher than the female one after the first year of life (Fig. 2), while it is reversed in P. subflawus (Davis, 1966). Most of the adult male $P$. abramus may become solitary or die within a year 
Table 3. Life table for the C population of female P.abramus from Fukuoka City in July 1965.

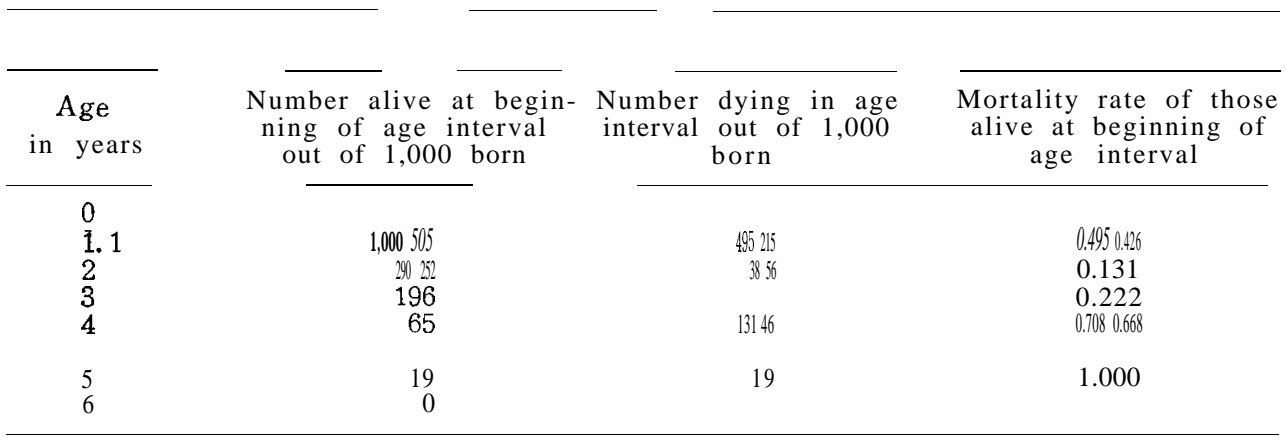

as stated in our previous paper (Funakoshi and Uchida, 1978). The greatest age determined for female $P$. abramus is five years (Fig. 2), the average span being 0.84 year (Table 3). The longest survival period gained from this study is very much shorter than those (from 10 to 20 years or more) of such other vespertilionids as E. fuscus (Beer, 1955; Hitchcock, 1965; Goehring, 1972; Schowalter et al., 1978), P. subflavus (Davis, 1966), Plecotus auritus (Stebbings, 1966), M.lucifugus (Griffin and Hitchcock, 1965 ; Hitchcock, 1965 ; Humphrey and Cope, 1976 ; Schowalter et al., 1978 ; Keen and Hitchcock, 1980), Myotis subulatus (Hitchcock, 1965), M. schreibersi (Dwyer, 1966 ; Kuramoto et al., 1975), M. sodalis (Humphrey and Cope, 1977) and M. macrodactylus (Kuramoto et al., 1978). Therefore, it should be noted that in $P$. abramus the constituent members of each colony are rather rapidly replaced by the younger generation, and the colony is mainly maintained by the females aged one or two years.

If the $\mathrm{C}$ population keeps its relatively stable age composition, we may assume that of 88 females aged more than one year, 31 would disappear in the next year (35.2 \% in disappearance rate). As mentioned above, about 51 volant young females might be produced in the $\mathrm{C}$ population, and the disappearance rate in females during the period from weaning to one year of age averages $24 \%$ (Table 2). Thus, the number of females added to the population in the following year may be estimated at about $39(51 \times 0.76)$, and the additional rate may become $44.3 \%$. Judging from the above, these percentages are sufficient to maintain the population at the same size in successive years, and consequently some of the young may be allowed to disperse without decline of the population itself.

Man has facilitated an increase in the population of M. lucifugus by providing more roosting sites that bats have been quick to locate and exploit, and thus availability of roosts is an important factor limiting bat populations (Fenton, 1970). The same explanation may well apply also to the housedwelling bat, P. abramus, which lives only in human habitations. Such ecological properties of $P$. abramus, as multiple births, early sexual maturity, rapid replacement of generation and tolerance for food shortage and unstable weather (Uchida, 1966; Funakoshi and Uchida, 1978, this paper) might be 
indispensable adaptations to human environment and population preservation.

\section{ACKNOWLEDGEMNTS}

We wish to thank the staff and graduate students of the Zoological Laboratory, Faculty of Agriculture, Kyushu University for their help and valuable discussion. We are also indebted to Mr. K. Marumo for using the banding data in 1971, and to Professor E. W. Jameson, Jr., University of California for comments on the manuscript.

\section{REFERENCES}

Beer, J. R. 1955 Survival and movements of banded big brown bats. J. Mamm., 36: 242248

Brenner, F. J. 1968 A three-year study of two breeding colonies of the big brown bat, Eptesicus fuscus. J. Mamm., 49: 775-778

Christian, J. J. 1956 The natural history of a summer aggregation of the big brown bat, Eptesicus fuscus fuscus. Amer. Midl. Nat., 55: 66-95

Davis, W. H. 1966 Population dynamics of the bat Pipistrellus subflavus. J. Mamm., 41: 383396

Davis, W. H. and H. B. Hitchcock 1965 Biology and migration of the bat, Myotis Iucifugus, in New England. J. Mamm., 46: 296-313

Dwyer, P. D. 1966 The population pattern of Miniopterus schreibersi (Chiroptera) in northeastern New South Wales. Aust.J. Zool., 14: 1073-1137

Fenton, M. B. 1970 Population studies of Myotis Iucifugus (Chiroptera: Vespertilionidae) in Ontario. Life Sci. Contrib. Royal O ntario Mus., 77: 1-34

Foster, G. W., S. R. Humphrey and P. P. Humphrey 1978 Survival rate of young southeastern brown bats, Myotis austroriparius, in Florida. J. Mamm., 59: 299-304

Funakoshi, K. and T. A. Uchida 1978 Studies on the physiological and ecological adaptation of temperate insectivorous bats. III. Annual activity of the Japanese housedwelling bat, Pipistrellus abramus.J. Fac. Agr., Kyushu Univ., 23 : 95-115

Funakoshi, K. and T. A. Uchida 1981 Feeding activity during the breeding season and postnatal growth in the Namie's frosted bat, Vespertilio superans superans. Jap. J. Ecol., 31: 67-77

Griffin, D. R. and H. B. Hitchcock 1965 Probable 24-year longevity records for Myotis Iucifugus. J. Mamm., 46: 332

Goehring, H. H. 1972 Twenty-year study of Eptesicus fuscus in Minnesota. J. Mamm., 53: 201-207

Herreid II, C. F. 1967 Mortality statistics of young bats. Ecology, 48: 310-311

Hitchcock, H. B. 1965 Twenty-three years of bat banding in Ontario and Quebec. Can. Field Nat., 79: 4-14

Humphrey, S. R. and J. B. Cope 1970 Population samples of the evening bat, Nycticei us humeralis. J. Mamm., 51: 399-401

Humphrey, S. R. and J. B. Cope 1976 Population ecology of the little brown bat (Myotis Iucifugus) in Indiana and north-central Kentucky. Spec. Publ. Amer. Soc. Mamm., 4: 181

Humphrey, S. R. and J. B. Cope 1977 Survival rates of the endangered Indiana bat, Myotis sodalis. J. Mamm., 58: 32-36

Humphrey, S. R. and T. H. Kunz 1976 Ecology of a Pleistocene relict, the western big- 
eared bat (Plecotus townsendii), in the southern Great Plains. J. Mamm., 57: 470-494

Humphrey, S. R., A. R. Richter and J. B. Cope 1977 Summer habitat and ecology of the endangered Indiana bat, Myotis sodalis. J. Mamm., 58: 334-346

Jones, J. K. Jr., E. D. Fleharty and P. B. Dunnigan 1967 The distributional status of bats in Kansas. Univ. Kansas Mus. Nat. Hist., Miscl. Publ., 46: I-33

Keen, R. and H. B. Hitchcock 1980 Survival and longevity of the little brown bat (Myotis lucifugus) in southeastern Ontario. J. Mamm., 61: 1-7

Klevezal, G. A. and S. E. Kleinenberg 1967 Age Determination of Mammals from Annual Layers in Teeth and Bones. Transl. by J. Salkind(1969), IPST Press, Jerusalem.

Kunz, T. H. 1971 Reproduction of some vespertilionid bats in central Iowa. Amor. Midl. Nat., $86: 477-486$

Kunz, T. H. 1974 Reproduction, growth, and mortality of the vespcrtilionid bat, Eptesicus fuscus, in Kansas. J. Mamm., 55: I-13

Kuramoto, T., H. Nakamura and T. A. Uchida 1978 Habitat selection, mode of social life and population dynamics in Myotis macrodactylus. Bull. Akiyoshi-dai Sci. Mus., (13) : 3554 (in Japanese with English abstract)

Kuramoto, T., H. Nakamura, 'T. A. Uchida and J. Shimoizumi 1975 A survey of batbanding on the Akiyoshi-dai Plateau. III. Results from April 1972 to March 1975.

Bull. Akiyoski-dai Sci. Mus., (11): 29-47 (in Japanese with English abstract)

Linhart, S. B. 1973 Age determination and occurrence of incremental growth lines in the dental cementum of the common vampire bat (Desmodus rotundus). J. Mamm., 54: 493-496

Lord, R. D.. F. Muradali and L. Lazare 1976 Age composition of vampire bats (D esmodus rotundus) in northern Argentina and southern Brazil. J. Mamm., 57: 573-575

Mumford, R. E. 1969 Long-tailed weasel preys on big brown bats. J. Mamm., 50: 360

Pearson, 0. P., M. R. Koford and A. K. Pearson 1952 Reproduction in the lump-nosed bat (Corynorhinus rajinesguei) in California. J. Mamm., 33: 273-320

Rice, D. W. 1957 Life history and ecology of Myotis austroriparius in Florida. J. Mamm., 38: $15-32$

Schowalter, D. B., L.D. Harder and B. H. Treichel 1978 Age composition of some vespertilionid bats as determined by dental annuli. Can. J. Zool., 56: 355-358

Stebbings, R. E. 1966 A population study of bats of the genus Plecotus. J. Zool.Lond., 150: 53-75

Stevenson, D. E. and M. D. Tuttle 1981 Survivorship in the endangered gray bat (Myotis grisescens). J. Mamm., $62: 244-257$

Taylor, W. P. 1954 Food habits and notes on life history of the ring-tailed cat in Texas. J. Mamm., 35: 55-63

Tuttle, M. D. 1976 Population ecology of the gray bat (Myotis grisescens): factors influencing growth and survival of newly volant young. Ecology, 57: 587-595

Uchida, T. A. 1953 Studies on the embryology of the Japanese house bat, Pipistrellus tralatitius abramus (Temminck). II. From the maturation of the ova to the fertilization, especially on the behaviour of the follicle cells at the period of fertilization. Sci. Bull. Fac. Agr., Kyushu Univ., 14: 153-168 (in Japanese with English summary)

Uchida, T. A. 1966 Mammals of Japan (5): Order Chiroptera, Genus Pipistrellus. Honyurui Kagaku (Mammalian Science) (11) : 5-23 (in Japanese)

Wimsatt, W. A. 1945 Notes on breeding behavior, pregnancy, and parturition in some vespertilionid bats of the eastern United States. J. Mamm., 26:23-33 